Supplement of Atmos. Chem. Phys., 19, 7507-7518, 2019

https://doi.org/10.5194/acp-19-7507-2019-supplement

C Author(s) 2019. This work is distributed under

the Creative Commons Attribution 4.0 License.

(c) (1)

\section{Atmospheric \\ Chemistry \\ and Physics}

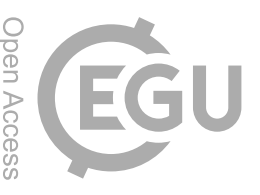

Supplement of

\title{
Optically effective complex refractive index of coated black carbon aerosols: from numerical aspects
}

Xiaolin Zhang et al.

Correspondence to: Mao Mao (mmao@nuist.edu.cn) and Xiaolin Zhang (xlnzhang@nuist.edu.cn)

The copyright of individual parts of the supplement might differ from the CC BY 4.0 License. 

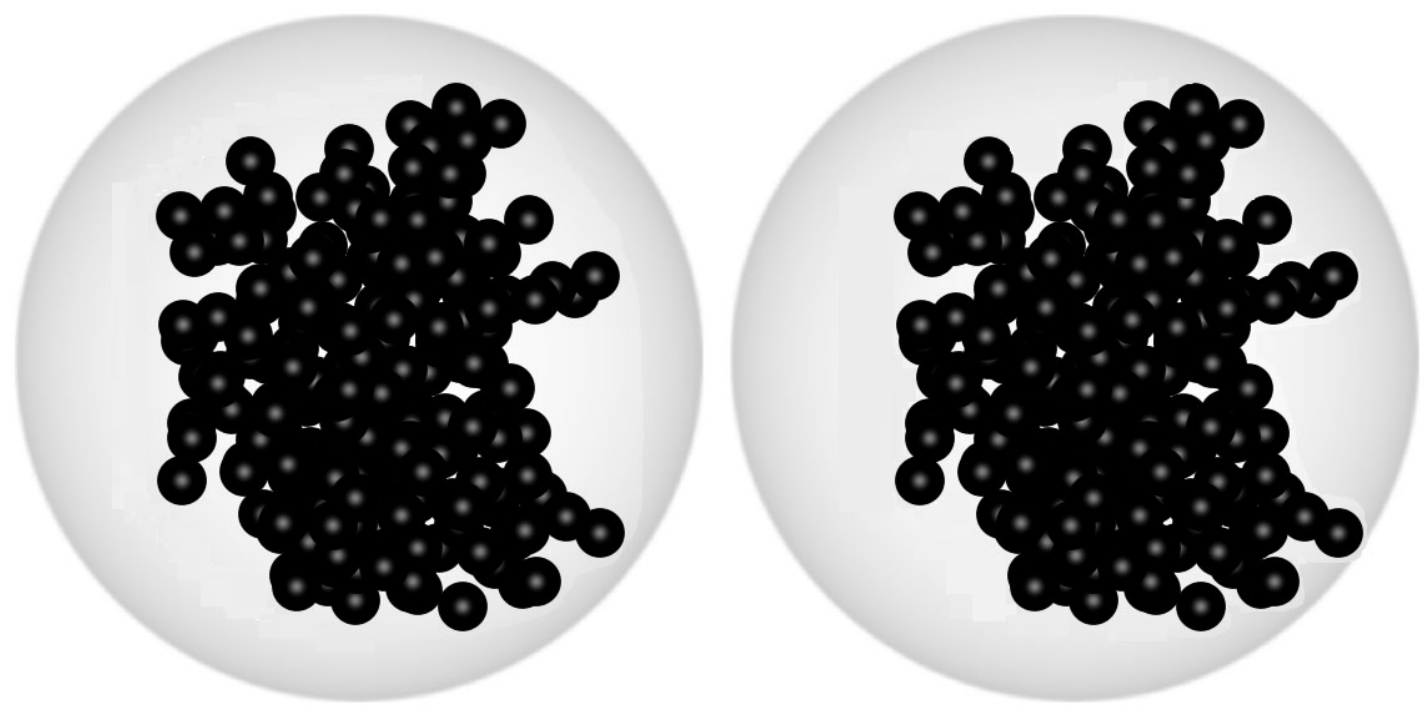

Fig. S1. Sketch map of geometry of coated black carbon for two off-center core-shell structures. One is $\mathrm{BC}$ aggregates locating at the middle of a radius of coating sphere (left), and the other is BC at an outer position as close as possible to coating boundary (right). The examples of fractal black carbon aggregates, containing 200 monomers, are coated by sulfate. 

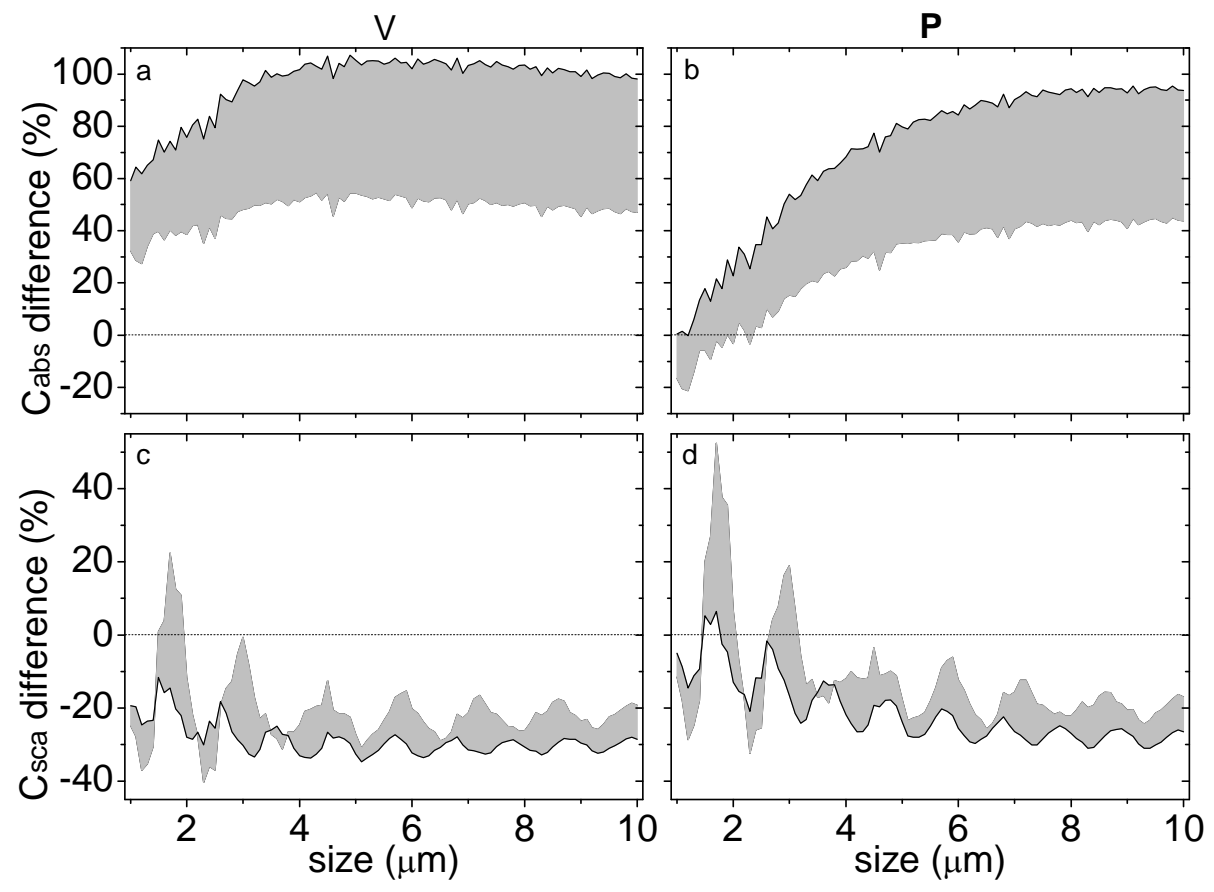

Fig. S2. Comparisons between the relative differences of scattering and absorption coefficients of coarse coated black carbon aggregates at different size induced by the refractive indices based on the volume weighted average method (a, c) and those given by the parameterized method described by Equations $7 \& 8$ in the main text (b, d). The BC fractal dimension of 2.8 and shell/core ratio of 2.7 are considered, and the induce differences for absorption and scattering cross sections are shown in top and bottom rows, respectively. The solid lines indicate the cases of core-shell structures with $\mathrm{BC}$ at an outer position as close as possible to coating boundary while the gray areas denote the cases of all possible core-shell structures with BC aggregates inside sulfate coating. The dash lines denote no differences. 